February 2013

\title{
Clinical application of Nightingale's environmental theory
}

Shirin Rahim

Aga Khan University, shirin.rahim@aku.edu

Follow this and additional works at: https://ecommons.aku.edu/pakistan_fhs_son

Part of the Nursing Midwifery Commons

\section{Recommended Citation}

Rahim, S. (2013). Clinical application of Nightingale's environmental theory. i-manager's Journal on Nursing, 3(1), 43-46.

Available at: https://ecommons.aku.edu/pakistan_fhs_son/151 


\title{
CLINICAL APPLICATION OF NIGHTINGALE'S ENVIRONMENTAL THEORY
}

\author{
By \\ SHIRIN RAHIM \\ Aga Khan University School of Nursing, Karachi, Pakistan.
}

\begin{abstract}
This paper analyze a clinical scenario in light of Nightingale's environmental theory and its three canons (ventilation, bed and bedding and personal cleanliness), and propose hypothesis which can be used to test a nursing intervention based on Nightingale's theory to change the unpleased outcome of this and more like scenarios.
\end{abstract}

Keywords: Notes on Nursing, Nightingale's Environmental Theory.

\section{INTRODUCTION}

Florence Nightingale (1820-1910) the first nursing theorist and the first one to lay the foundation of modern nursing has based her philosophy on spiritualism. Selanders (2010) quotes (Cook, 1913, Vol. 1, p. 15) in saying, that "She records in her diary an interaction with God at age 16 when He "called her to His service" (p.82). Her devotion towards God and her belief of spirituality was the foundation of almost all that Nightingale did as a nurse and for nursing profession. (Allighood and Tommy 2010). Nightingale has taken the same premise for her environmental theory. In this theory Nightingale (1860) has emphasized that nature has some laws which if applied correctly on humans, help those who are ill to restore health and those who are healthy to remain prevented from illness and promote health.

There are seven assumptions of nightingale's theory. According to Selanders (2010). Seven Nightingalean philosophical assumptions are identified and serve as the basis for the model development. These assumptions are natural laws; mankind can achieve perfection; nursing is a calling; nursing is an art and a science; nursing is achieved through environmental alteration; nursing requires a specific educational base; and nursing is distinct and separate from medicine (pp 83-84).

The concepts of Nightingale's theory are the metaparadigm of nursing, that is person, health, nursing, and environment are very strongly connected to each other. Here person is a multidimensional being on which a nurse acts. Disease, as per Nightingale (1860) is a process given by nature to clean the body from impurity which has entered into the body because one or more of body's natural need is not fulfilled or one or more of the natural laws are not being applied. Disease actually indicates a want of the body in terms of natural laws, and by making some changes in environment these wants can be satisfied and disease can be cured. It is like this, Nightingale assumes that mankind can achieve perfection.

According to Nightingale (1860), All disease, at some period or other of its course, is more or less a reparative process, not necessarily accompanied with suffering: an effort of nature to remedy a process of poisoning or of decay, which has taken weeks, months, sometimes years beforehand, unnoticed. Pain and suffering, which in patients are the symptoms not of their disease but of the absence of one or all of the above mentioned essentials to the success of natures reparative processes. (p. 1\&3)

Nightingale has also said that lack of natural laws not only affect the sick but the healthy one also. According to Nightingale (1860), "the same laws of health obtain among the well as among the sick. The breaking of them produces, only less violent consequences among the former then among the latter" (p.4)

Nursing in Nightingale's view is an art of how to let nature work on humans to make the ill healthy and the healthy remain the same. However a nurse is the one who makes such conditions in which these laws are easily applicable on patients to achieve the desired health status. As Nightingale (1860) in notes of nurses says, "If a patient is 
cold, if a patient is feverish, if a patient is faint, if he is sick after taking food, if he has a bed-sore, it is generally the fault not of the disease, but of the nursing" (p. 2). On this Selanders (2010), comments by saying "The implication is clear, the nurse is responsible for maintaining the environment in such a manner as to maintain the health of the patient" (p.86). So a nurse should identify why patient is having the suffering and which of the nature's law is the need of the patient and how this can be achieved by changing the environment. That is why Nightingale proposed the assumptions that nursing is an art and a science, nursing is achieved through environmental alteration, and nursing requires a specific educational base. Every woman according to Nightingale is a nurse, if she fulfils above assumption. Nightingale (1860), has very strongly emphasized that only getting medical advice or medication is not enough, and nursing is not only administering the medication prescribed by doctors but to cure disease, one must understand body's need for the natural law application and work accordingly. This according to Nightingale, is nursing and here nursing becomes distinct from medicine. Nightingale (1860) says that "I use the word nursing for want of a better. It has been limited to signify little more than the administration of medicine...the proper use of fresh air, light, warmth, cleanliness, quiet, and proper selection and administration of diet" (pp 2-3).

Finally the environment is the means through which a nurse can make application of natural laws on a patient possible, if environment is kept such, that the natural laws can easily act on human body and disease goes off but the opposite happens when environment is not maintained properly. According to Selanders (2010), "Environment is the umbrella concept in the Nightingale theory of nursing. It was her contention that the environment could be altered in such a manner as to improve conditions so that the natural laws would allow healing to occur" (p.84).

The 13 sub concepts of environment which are called canons by Nightingale (1860) are actually the conditions which if adequately present in the environment help in healing. These are ventilation and warming, health of houses, petty management, noise, variety of taking food, bed and bedding, light, cleanliness of rooms and walls, personal cleanliness, chattering hopes and advices, and observation of the sick. While analyzing the scenario in light of the theory the author has a brief on ventilation, bed and bedding and personal cleanliness (as her scenario covers these).

\section{Client's Scenario}

Mrs. A, a 60 years old lady who had recently undergone coronary artery bypass grafting was the eldest member of the family who was the author's client in community clinical during her undergrad studies in 2009. It was a middle class family comprising of four members, living in a two room apartment. On entering the house for the first time, the author experienced an unpleasant odor throughout the house, as only one window of the house was open due to which the house was although bright, but was not well ventilated.

While assessing Mrs. A, it was revealed that since last one day she was feeling pain, itching and redness in her stitches, and her body temperature was also raised. Her wound was red and had little purulent discharge, and her temperature was 38 degree centigrade. Mrs. A, actually had developed infection in the wound, and required hospitalization without any delay. While mobilizing Mrs. A from bed to chair it was noticed that her bed linen was also dirty and wrinkled. On inquiring from her daughter-in-law, it was identified that the bedding was not changed since last one week as she does not come out of her bed for so long that the bed linen could not be changed. Also on inquiry, it was told that Mrs. A is being given assisted bath only twice a week and even her clothes are not changed daily.

As intervention, the author helped Ms. A's daughter in law in changing the bedding and giving bath to Mrs. A. She also taught her techniques for sponging, as if she cannot take Mrs. A for bath every day she can give her sponge daily twice a day. She made all the windows open and made the house brighter and more ventilated, and took personal and bed hygiene as a topic and provided a session to whole community.

Applying Nightingale's Environmental Theory to the Scenario

Using Nightingale to explain the above stated scenario, the 
author would say that Mrs. A was the person who required nursing, her wound infection was the disease given by nature to stress that due to improper environment that is closed windows, dirty bed linen and lack of self care, Mrs. A's body is not getting the best conditions which are ventilation, and self hygiene. A nurse having this knowledge, and using her artistic abilities should alter Mrs. A's environment in such a way that her body gets what it wants so that nature's laws will be applicable on her to cure the disease. The nurse in this scenario was Mrs. A's daughter-in-law who if, have identified the needs and altered the environment accordingly, the wound infection would not have occurred. But unfortunately this could not happen. Lately, as the author assumed the place of nurse and with the nursing knowledge, she posses she tried to alter the environment (opened windows, given bath and changed bedding) of Mrs. A so that the infection (disease) can be controlled and got diminished. Although the author had never directly associated ventilation as the cause of the disease, (which she can relate now after reading Nightingale), she also sent her for follow-up and necessary medication which is a generally accepted phenomenon (even among nurse) that every disease should need medical attention.

Let us analyze this scenario in light of Nightingale's theory, that how Mrs. A's environment affected her and what were the other determinants that exaggerated the outcome of the scenario that was the wound infection. According to Nightingale's theory, Mrs. A's body wanted conditions, like proper ventilation, and good self hygiene for nature to apply its law to heal Mrs. A's surgical wound but as this want of the body was not fulfilled, nature displayed this need in form of a disease (wound infection) so that a nurse can pick this need and alter Mrs. A's environment for nature to apply laws in curing her surgical wound. Let us explore how ventilation, and self hygiene would affect a person's health condition.

Ventilation and warmth is the first canon of Nightingale's theory in which she has emphasized how a sick person's room should be, for nature to act upon him. The list includes aeration of room with out side fresh air, warmth of the room, freshness of night air, avoidance of fumigation and foul smells etc. According to Allighood and Tommy (2010), "Nightingale's emphasis on proper ventilation indicates that she seemed to recognize this environmental component as a source of disease and recovery" (p75). Nightingale (1860) has very nicely explained the consequence of improper ventilation by saying "we nose the murderers in the musty, unaired, unsunned room, the scarlet fever which is behind the door or the fever or hospital gangrene" (p10). Commenting on foul smell in houses Nightingale (1860) commented "during sleep, the human body, even when in health, is far more injured by the influence of foul air. . . keep the air all night ... as pure as the air without....you must have open windows or ventilations" (p13).

Bed and bedding be the eighth canon, has also been very nicely related with patient's health. Nightingale believed that patients who are on bed rest deposit their own harmful floras on the bed and if the bedding is not changed frequently, it becomes saturated with these floras, which gets re-entered into patient's body causing more harm. (Nightingale 1860 .p 111.). For this reason Nightingale emphasizes airing of bed clothes.

According to Nightingale (1860), An adult-in-health exhales by the lungs and skin in the twenty-four hours, three pints at least of moisture, loaded with organic matter ready to enter into putrefaction; that in sickness the quantity is often greatly increased, the quality is always more noxious -where does all this moisture go to? Chiefly into the bedding ... And it stays there; because, except perhaps a weekly change of sheets, scarcely any other airing is attempted. (p. 112).

Talking about personal cleanliness, Nightingale (1860) has compared an unwashed skin of a patient with slow poison as she says that "if she allows her sick to remain unwashed or their clothing to remain on them ... she is interfering injuriously with the natural processes of health... as if she were to give the patient a dose of slow poison" (p. 133). In this canon Nightingale (1960), has very strongly advised nurses to take care of patient's personal hygiene. Not only this, but she has emphasized on use of soft water and taught methods of effective sponging to patients and even stressed, nurses own hand washing to prevent them from 
getting their patient's disease or infection.

As in Mrs. A's scenario all the above matters were not taken care so she ended up having wound infection, which would have been prevented otherwise.

Let us now explore some determinants or local context (added to improper ventilation and poor hygiene) which affected this scenario. First of all the age, and the health status of Mrs. A, which were too extreme for immunity to be strong made Mrs. A prone to get the infection, then the care taker (daughter-in-law) of Mrs. A was too busy with other house hold and babysitting tasks that she hardly could give quality time to Mrs. A, and Mrs. A's hygiene was badly compromised, leading to penetrate her own harmful floras into her body and causing the infection. Also the daughter-in-law was not aware of all these environmental influence for which if known, she would have taken care of. Mrs. A and the family had the perception that keeping the house warm is better for a sick person, so that they kept all windows closed, and Mrs. A went on inhaling injurious fumes resulting in infected wound.

Hypothesis to Test Nursing Interventions Based on Nightingale's Theory

The proposition or hypothesis which can be used to test a nursing intervention to change the unpleased outcome of this and more like scenarios can be:

- If the environmental measures that Nightingale identifies such as proper ventilation, and good self, bed hygiene, are emphasized during hospital stay and particularly as discharge teaching to all patients undergoing coronary artery bypass surgery, and if these intervention are given to patients, printed on a discharge summary it can prevent patient from getting the wound infection.

- If a session is taken for all the patients undergoing coronary bypass and their immediate care takers, (either pre or post surgery) regarding importance of proper ventilation, and good self, hygiene in preventing wound infection, with demonstration for sponging and hand washing techniques, it would prevent infections. With this proposition, we will probably take care of few assumptions of Nightingale's environmental theory such as natural laws; nursing is an art and a science and nursing is achieved through environmental alteration.

\section{Conclusion}

This scholarly exercise was an eye opening opportunity for the author to appreciate how this former nursing leader has combined knowledge of her empirics, arts and ethics to develop such a simple but so general and easy to apply theory with basic concepts in nursing. Today however advances have been achieved, but the reality and the importance of Nightingale's theory is at the highest rank, and if followed religiously nurses and other care takers at home can easily prevent several disease from occurring. This exercise has encouraged the author to make attempts to understand and apply other nursing theories also where ever they are applicable, to mark the difference in nursing practice and show to others the knowledge and the distinct nature of nursing. Although this knowledge is there since long, it is very sad to learn that even at graduate level the author had never emphasized at such details and only by reading theoretically applying this theory she could know how nursing can be an art.

\section{References}

[1]. Nightingale, F. (1860). Notes on Nursing: what it is and what it is not. London; Harrison, 59, Pall mall, bookseller to the Queen.

[2]. Selanders, L.C. (2010). The Power of Environmental Adaptation: Florence Nightingale's Original Theory for Nursing Practice. Journal of Holistic Nursing. (28) 81-88.

\section{ABOUT THE AUTHOR}

Aga Khan University School of Nursing, Karachi, Pakistan. 